\title{
Management of Separated Instrument in Apical Part of Mandibular Molar by Intentional Reimplantation. - A Case Series.
}

\author{
S.Thillainayagam ${ }^{1}$ M.D.S., , S.Karthikeyan2 M.D.S., N.Bharath ${ }^{3}$ M.D.S., \\ Abishekrajarambalaji ${ }^{4}$ M.D.S., \\ ${ }^{I}$ Professor And Head Of The Department, Department Of Conservative Dentistry \&Endodontics, \\ Adhiparasakthi Dental College \&Hospital, Melmaruvathur. \\ ${ }^{2},{ }^{3}$ Senior Lecturer, Department Of Conservative Dentistry \&Endodontics, Adhiparasakthi Dental College \\ \&Hospital, Melmaruvathur. \\ ${ }^{4}$ Senior Lecturer, Department Of Oral And Maxillofacial Surgery,Adhiparasakthi Dental College \&Hospital, \\ Melmaruvathur.
}

\begin{abstract}
The fracture of an instrument is a recognized complication in endodontics. The immediate response to a fractured instrument is frequently to regard the treatment as a failure. Several factors must, however, be taken into account to evaluate the prognosis of the tooth in this situation. The objective of the endodontic treatment with or without a fractured instrument remains the same, namely to disinfect the root canal system and prevent its recontamination. The time at which file fracture occurred during treatment and the degree of canal infection should be considered when determining the potential effect of instrument fracture on treatment outcome. Patients must be informed about an instrument fracturing in their tooth for ethical and legal reasons. This article explains about successful management of separated instrument in apical part of mandibular molar.

Keywords:Intentional reimplantation, Separated instrument.
\end{abstract}

\section{Introduction}

Intentional reimplantation is defined by grossman, as the "removal of a tooth and its almost immediate replacement, with the objective of obturating the canals apically while the tooth is out of the socket [1]". Bender and rossman reported a success rate of $81 \%$ of 31 teeth followed up for 22 years. [2] Tooth reimplantation has a long history. At the eleventh century $\mathrm{AD}$, Abulcasis described the first account of replantation and use of ligatures to splint the replanted teeth [3]. In 1712, Pierre faucharddid a case of Intentional replantation fifteen minutes after extraction[4]. Intentional replantation for mature and immature teeth in 1768reported by Thomas berdmore[5]. John hunter believed that boiling the extracted tooth prior to replantation may help to remove the tooth disease in 1778[6].

Role of periodontal ligament in prognosis of replanted teeth given by scheff in 1890[7]. In 1955, hammer described the importance of leaving an intact PDL on intentionally replanted teeth[8]. In 1971, Leo and waerhaug tried to replant teeth immediately to keep the PDL vital[9]. Resultantly, ankylosis was not seen: however, all teeth showed resorption repaired with cementum. These results have been confirmed by Deed in 1965 and Edwards in 1966[10]. In 1968, Sherman showed that normal pdl could be re-established following intentional reimplantation[11].

This case report describes a case report of intentional reimplantation of separated instrument in mesial canal of mandibular teeth. Attempts to remove separated instruments from the root canal done. But unsucessful attempt to remove the instrument made the option of intentional reimplantation.

\section{Case Report}

A 14 years old boy reported to the Out Patient Department of Conservative Dentistry and Endodontics, Adhiparasakthi Dental College and Hospital with a chronic swelling in relation to right posterior mandibular region. Thorough case history of the patient was undertaken, on history taking, the patient gave a history of separated instrument in the mesial root of the mandibular molar and re-attempt done to remove the separated instrument and it was failed.On intra oral examination it revealed root canal treated 46 associated with intra oral swelling. Coronal seal was intact and patient had tender on percussion.

On radiographic examination the tooth shows complete obturated canal with findings of separated instrument in apical part of mesial root of mandibular molar. The root was severely curved, peri-apical region of mesial root shows moderate periapical radiolucency with widening of periodontal space and no alveolar bone loss (Fig.1.a). 
The patient wants the tooth to be extracted. The patient father was informed about the consequence of early loss of first molar and explained about importance of first molar for mastication, occlusal stop and also integrity of dentition.

Treatment options explained to the patient's father and the decision of intentional re-implantation obtained from him.

1. Extraction of mandibular first molar followed by removable prosthesis till the growth complete followed by fixed prosthesis.

2. Intentional extraction of mandibular first molar followed by apicetomy and re-implantation.

In the second option, the success rate explained to the patient and the chances of fracture of root and also informed if second option fails, switch over to first option. The patient father accepted to go for second option, written consent was obtained from the patient's father to continue the treatment.

Antibiotics and analgesics are given to the patient for next four days before starting the treatment.

\section{Procedure Of Intentional Re-Implantation:}

Chlorhexidine mouth wash $(0.2 \%)$ given for rinsing the mouth before treatment. Periosteal elevator was used to luxate the tooth and it was extracted by mandibular forceps as atraumatic procedure (Fig. 1b). Care was taken to avoid to touch the root surface to maintain the viability of periodontal tissues, also precautions to be taken to decrease the extra oral time of extracted teeth as minimum as possible.

The apical part of the tooth was resected along with fractured instrument (Fig.1.c) and retrograde preparation done and restored with Mineral Trioxide Aggregate (Fig.1.e). The root surface was kept intermittently to avoid dehydration of the Pdl cells.

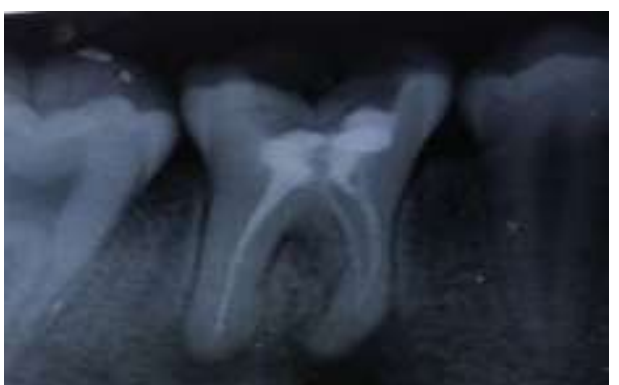

Fig.1a. Pre-Operative radiograph

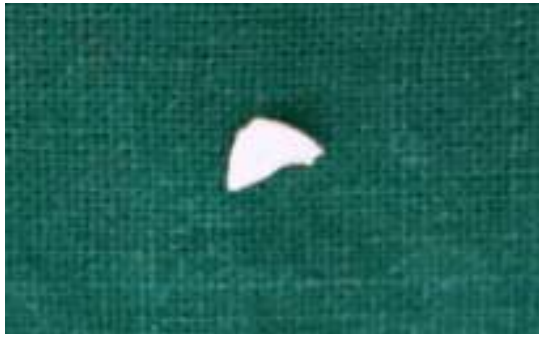

Fig.1.c. Removal of apical part of root.

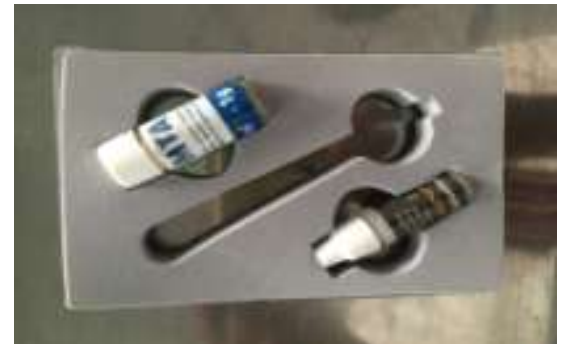

Fig.1.E. MTA used for retrograde restoration.

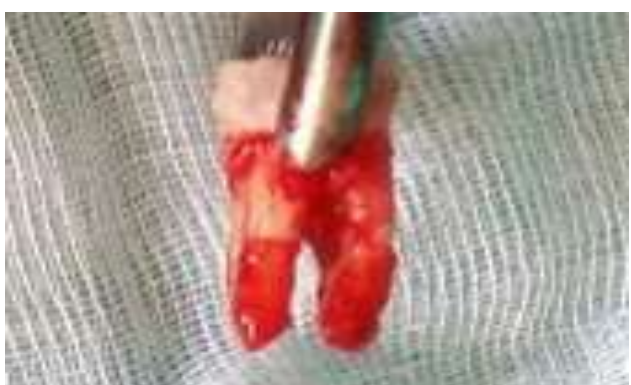

Fig.1.b. Extraction of teeth for removal of fractured segments

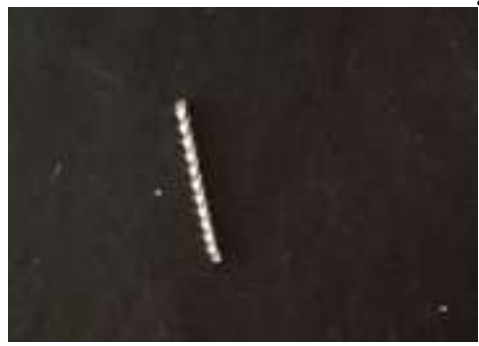

Fig.1.D. Removal of Separated instrument.

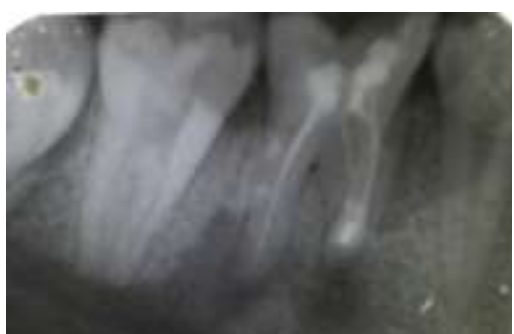

Fig.1.F. Retrograde restoration with MTA(Post-Operative)

Meanwhile, the operator curette the granulation tissue presents in the socket and induces fresh bleeding. The teeth was reimplanted in the socket. Extraoral time recorded for this procedure was only four minutes.

Suturing done around the re-implanted teeth using 3-0 silk and radiograph was taken to confirm the complete removal of instruments. Patient recalled after 24 hours to check for post operative complaints and patient was completely asymptomatic and after one week of post operative period the patient asked to come for suture removal and it was done. 


\section{Discussion}

Intentional replantation is a viable alternative in cases of unsuccessful endodontic procedure. The patient were called for 2 year follow up study and examined. The patients were completely asymptomatic. The success or failure rate of intentional replantation depends on viability of pdlcells[12].After extraction and before reimplantation the alveolus must be delicately curetted and irrigated with saline to prevent exceesive bleeding[13].

\section{Factors influencing the periodontal healing are}

1. The extraoral time should me as minimum as possible to maintain the viability of pdlcells $[14,15]$. This case report taken only 4 minutes to replant the avulsed teeth.

2. Root surface with rootend filling material seens more successful than replantation without rootend filling material[16].

3. The root surface should be avoided to touch to maintain the viability of periodontal ligament cells [17].

4. Single rooted teeth has more success rate than multi rooted tooth[18].

5. The root surface should be bathed with normal saline to maintain the viability of pdl cells.

During the procedure of intentional reimplantation we took care of forceps beaks should not touch the cementum to avoid damage to the pdl cells. The success of this procedure also depends on the ability to remove the involved tooth without fracture of the root or roots. The patient should always be advised that fracture of the tooth is possible and if this occurs, the tooth must be removed and discarded.

Advantages of Intentional replantation over apical surgery are it is an easier, less-invasive, less timeconsuming, and less-costly procedure. In addition, root canal therapy is better performed extraorally. On the other hand, the greatest disadvantage of intentional replantation, which leads most dentists to consider this technique as a last resort to save a tooth, is that replacement resorption or ankylosis may occur. However, recent long-term studies[19] have shown that the success rates for intentional replantation are similar to those for apical surgery if the extra oral time is minimal.In this case reports ,Clinical and radiographic success was based on mobility test, probing depth, clinical attachment level, absence of root resorption and alveolar bone integrity. Kratchman stated, "With increased understanding of the periodontium and improved techniques, intentional replantation should no longer be viewed as a treatment of last resort, but rather a successful treatment alternative.

\section{Conclusion}

In conclusion, intentional reimplantation is an effective treatment modality when normal endodontic procedures are unsuccessful. In this case report, 2 year follow up study of intentional reimplantationas an alternative treatment option to remove separated instrument with respect to mandibular first molars and patients were free of symptoms.

\section{References}

[1]. Grossman. LI.Intentionalreimplantation of teeth; A clinical evaluation.Jounal of American dental association;1982;104;633-39

[2]. Bender IB, Rossman LE. Intentional replantation of endodontically treated teeth. Oral Surg. 1993;76:623-630

[3]. weinbergerB.Introduction to the history of dentistry. St. Louis;Mosby,1948.

[4]. Fauchard P. Le chirurgien dentist outraitedes'dents. Paris; chez pierre-Jean Mariette 1746.

[5]. Bredmore T. A treatise on the disorders and the deformities of the teeth and gums. London; white ,dodsley,Beckett and deHondt. 1768

[6]. Woffendale R. Practical observations on the teeth. London ; J. Johnsan 1783.

[7]. Hunter H. A Practical treatise on the diseases of the teeth. London. J Johnsan 1778.

[8]. Scheff J. Die Replantation der Zahne. OstVjschrZahnheilkd 1890; 2:181-278.

[9]. HammerH.Reimplantation and implantation of teeth. Int Dent J.1955;5;439-57

[10]. Loe H, WaerhaugJ.Experimental replantation of teeth in dogs and monkeys.Arch Oral Biol 1961;3;176-84

[11]. Deeb E, prietto PP Mckenna RC. Reimplantation of Luxated teeth in humans. J South California Dental Association 1965; 33;194206.

[12]. ShermanPJr.intentional replantation of teeth in dogs and monkeys. J Dent Res 1968;47(6);1066-71.

[13]. Register A, Burdick F. Accelerated reattachment with cementogenesis to dentin, demineralized in situ. II. Defect repair. J Periodontol 1976; 47: 497-505..

[14]. Dryden JA, Arens DE. Intentional replantation. A viable alternative for selected cases . Dent Clin North AM 1994:38;325-53.

[15]. Deeb E, Prietto PP, Mckenna RC. Reimplantation of Luxated teeth in humans. J South Calif Dent association 1965;33;194-206.

[16]. Register A, Burdick F. Accelerated reattachment with cementogenesis in dentin, demineralized in situ. I. Optimum range. J Periodontol 1975; 46: 646-55

[17]. Grossman L J. Intentional replantation of teeth. In: Robinson P J, Guernsey L H. Clinical transplantation in dental specialities. 1. ed. St. Louis, USA: Mosby; 1980. P. 65-76.

[18]. Andreasen J O. Analysis of pathogenesis and topography of replacement root resorption (ankylosis) after replantation of mature permanent incisors in monkeys. Swedish Dent J 1980; 4: 135-44.

[19]. Benenati FW. Intentional replantation of a mandibular second molar with long-term follow-up: report of a case. Dent Traumatol 2003;19:233-6. 